\title{
Is there a need for adjunct cerebral protection in conjunction with deep hypothermic circulatory arrest during noncomplex hemiarch surgery?
}

\author{
Tsuyoshi Kaneko, MD, Sary F. Aranki, MD, Robert C. Neely, MD, Farhang Yazdchi, MD,
} Siobhan McGurk, BSc, Marzia Leacche, MD, and Prem S. Shekar, MD

\begin{abstract}
Objective: Different cerebral protection strategies are currently being practiced during noncomplex hemiarch surgery without randomized control studies to show their relative efficacy. We hypothesized that deep hypothermic circulatory arrest (DHCA) alone was adequate for cerebral protection in noncomplex hemiarch surgery.
\end{abstract}

\begin{abstract}
Methods: Four hundred sixty-seven patients underwent noncomplex hemiarch surgery between January 2002 and December 2012. Calcified aortas and total arch surgeries were excluded. DHCA alone was used for 276 patients, DHCA with antegrade cerebral perfusion (ACP) was used for 114 patients, and DHCA with retrograde cerebral perfusion (RCP) was used for 77 patients.
\end{abstract}

\begin{abstract}
Results: Preoperative characteristics were similar between groups $(12.3 \%$ in the DHCA group, $12.3 \%$ in the ACP group, and $10.3 \%$ in RCP group were reoperations). Patients in the DHCA group had shorter cardiopulmonary bypass times (193 minutes vs 217 minutes; $P \leq .005)$ and total lower body ischemic times ( 21 minutes vs 30 minutes; $P \leq .001$ ) than ACP, but not RCP. Rates of reoperations for bleeding, postoperative stroke, and new renal failure did not differ between groups. New onset of cerebrovascular events were seen in $5.4 \%$ of patients in the DHCA group versus $6.2 \%$ of patients in the ACP group and $6.4 \%$ of patients in the RCP group (all $P$ values $>.7$ ). Operative mortality in the DHCA group was $4.7 \%$ versus $2.6 \%$ in the ACP group and $2.6 \%$ in the RCP group (all $P$ values $>$.4). Cox proportional hazard modeling showed no survival differences between groups.
\end{abstract}

Conclusions: Outcomes and survival using DHCA alone were comparable to adjunct cerebral protection methods in patients undergoing noncomplex hemiarch surgery. DHCA alone is as safe as other adjunct complex cerebral protection techniques and simplifies operation without additional risk. (J Thorac Cardiovasc Surg 2014;148:2911-7)

See related commentary on pages $2917-9$.

Deep hypothermic circulatory arrest (DHCA) revolutionized the surgical treatment for aortic arch disease. ${ }^{1}$ The introduction of DHCA dramatically improved the safety of the operation, although longer durations of circulatory arrest are associated with increased neurologic complications. Even with DHCA at $18^{\circ} \mathrm{C}$, there remains a $12 \%$ to $25 \%$ cellular metabolic rate compared with normal body temperature. ${ }^{2}$ The threshold for increased incidence of neurologic complications has been reported to be at DHCA time of 25 to 40 minutes. $^{3-6}$ To overcome this limitation, 2 adjunctive

From the Division of Cardiac Surgery, Brigham and Women's Hospital, Boston, Mass.

Disclosures: Authors have nothing to disclose with regard to commercial support.

Read at The American Association for Thoracic Surgery Aortic Symposium 2014,

New York, New York, April 24-25, 2014.

Received for publication May 15, 2014; revisions received July 15, 2014; accepted for publication Aug 7, 2014; available ahead of print Sept 26, 2014.

Address for reprints: Prem S. Shekar, MD, 75 Francis St, Boston, MA (E-mail: pshekar@partners.org).

$0022-5223 / \$ 36.00$

Copyright (C) 2014 Published by Elsevier Inc. on behalf of The American Association for Thoracic Surgery

http://dx.doi.org/10.1016/j.jtcvs.2014.08.010 strategies have been introduced, namely antegrade cerebral perfusion (ACP) and retrograde cerebral perfusion (RCP). These techniques are used in addition to the already established hypothermic circulatory arrest technique.

Multiple studies have been conducted to identify the safest cerebral protection strategy, and the answer remains controversial. ${ }^{7-12}$ No randomized control study has been conducted to demonstrate the superiority of 1 technique over the other. Most of the previous studies have compared the outcomes in the aortic arch, which combines the outcomes of both total arch replacement and hemiarch replacement.

The advantage of DHCA alone is the simplification of the procedure by avoiding complex adjunctive cannulation and perfusion, but it is limited by a shorter acceptable circulatory arrest time. We defined noncomplex hemiarch surgery as hemiarch surgery performed for aneurysm or dissection, but not for calcified aorta, total arch replacement, or other etiologies. Our hypothesis was that, in noncomplex hemiarch surgery, which typically requires shorter circulatory arrest time, DHCA alone was safe and adjunctive strategies are not needed.

The aim of our study was to assess the mortality and morbidity, particularly neurologic complications, from noncomplex hemiarch surgeries using different cerebral protection strategies and identify whether DHCA alone is safe compared with adjunctive strategy of ACP and/or RCP. 


$$
\begin{aligned}
& \text { Abbreviations and Acronyms } \\
& \text { ACP }=\text { antegrade cerebral perfusion } \\
& \text { CVA }=\text { cardiovascular accident } \\
& \text { DHCA }=\text { deep hypothermic circulatory arrest } \\
& \text { ICU }=\text { intensive care unit } \\
& \text { LOS }=\text { length of stay } \\
& \text { RCP } \\
& \text { TIA }=\text { retrograde cerebral perfusion }
\end{aligned}
$$

\section{METHODS}

\section{Patients and Exclusion Criteria}

We identified 467 consecutive patients who underwent noncomplex hemiarch surgery at our institution between January 2002 and December 2012. We defined noncomplex hemiarch surgery as hemiarch surgery for aortic aneurysms, acute and chronic dissections without arch replacement, and excluded operations with calcified aortas. The choice of cerebral protection strategy was decided by surgeon's preference. This study was approved by the Institutional Review Board of Brigham and Women's Hospital.

\section{Operative Technique}

Cerebral monitoring was performed using right radial arterial pressure, electroencephalogram, and bispectral index (Phillips, Eindhoven, Netherlands). In addition, we have used near-infrared spectroscopy cerebral monitoring since 2006. All patients underwent median sternotomy. Arterial cannulation was achieved either directly through the aorta $(69 \% ; 322$ out of 468 patients), via right axillary artery $(21 \%$; 97 out of 468 patients), or femoral artery ( $10 \%$; 48 out of 468 patients). One patient required direct innominate artery cannulation $(<1 \% ; 1$ out of 468 patients). For both the right axillary and femoral arterial cannulation, a side-arm graft technique, with a 6- to 10-mm graft, was used to avoid distal limb ischemia. Our cannulation strategy was based on surgeon preference; however, for most cases our first choice of cannulation for DHCA and/or RCP is direct aortic cannulation unless it is a reoperation or chronic dissection in which right axillary or femoral artery is used. When ACP is used, we prefer right axillary cannulation for cerebral perfusion. For venous drainage, the right atrium was cannulated using 3 -stage venous cannula. A left ventricular vent was inserted through the right superior pulmonary vein or left ventricular apex. Patients were cooled to around $18^{\circ} \mathrm{C}$ until the electroencephalogram was isoelectric and systemic circulatory arrest was maintained at that point. Bispectral index and near-infrared spectroscopy were used as an adjunct and used as a trend rather than specific goal number to guide the degree of unilateral/bilateral hemispheric ischemia. The patient was placed in Trendelenburg position and the aorta was opened. We have no standard strategy of cooling; we cooled to the goal temperature paying attention to ventricular fibrillation and dilatation. Standard policy of rewarming was to keep the temperature difference between the body and cardiopulmonary bypass within $10^{\circ} \mathrm{C}$. Rewarming was completed when the bladder temperature, not nasopharyngeal temperature, was up to $35.5^{\circ} \mathrm{C}$.

In the case of DHCA alone, upon completion of the distal anastomosis and deairing, antegrade systemic perfusion was initiated through the aortic graft side-arm or direct aortic or other peripheral cannulation. The proximal anastomosis was performed while rewarming.

For ACP, antegrade perfusion from the right axillary artery was initiated after internal inspection of the aorta and the innominate artery was clamped with cerebral perfusion established through the right carotid artery. The left internal carotid artery was also snared/clamped to pressurize the cerebral circuit. Flow rates were kept around $10 \mathrm{~mL} / \mathrm{kg} / \mathrm{min}$ to maintain the cerebral arterial pressure around 45 to $60 \mathrm{~mm} \mathrm{Hg}$ monitored by a right radial arterial line. When axillary artery cannulation was not used, the innominate artery was directly cannulated. On occasion, the left carotid artery was cannulated, if needed. The temperature of cerebral perfusion was at $18^{\circ} \mathrm{C}$. Following distal anastomosis, ACP was discontinued and antegrade systemic perfusion was resumed.

For RCP, the patient was bicavally cannulated. Cerebral perfusion was initiated through the superior vena cava before circulatory arrest and the superior vena cava was snared. RCP was maintained at flow rate of 100 to 300 $\mathrm{mL} / \mathrm{min}$ to keep the venous perfusion pressure, monitored by a central venous line, at $25 \mathrm{~mm} \mathrm{Hg}$ to avoid cerebral edema. The temperature of cerebral perfusion was $18^{\circ} \mathrm{C}$. Following the distal anastomosis, RCP was continued to back fill the aortic arch and graft for deairing and debris removal. RCP was then discontinued and antegrade systemic perfusion was initiated.

\section{Definition of DHCA Time, Cerebral Perfusion Time, and Total Lower Body Ischemic Time}

We defined DHCA time as cerebral circulatory arrest time. Cerebral perfusion time was total time of ACP and/or RCP time. Therefore total lower body ischemic time was equal to DHCA time in the DHCA group, DHCA time + ACP time (+RCP time) in the ACP group, and DHCA time $+\mathrm{RCP}$ time in the RCP group.

\section{Data Collection}

Patient characteristics, medications, laboratory values, and in-hospital outcomes of the index surgery were collected at the time of presentation and extracted from the hospital's electronic medical records. Data were coded according to The Society of Thoracic Surgeons National Adult Cardiac Database version 2.52 definitions unless otherwise noted.

The primary outcomes of interest were operative mortality; frequency of postoperative complications, mainly cerebrovascular accident (CVA) and transient ischemic attack (TIA); and long-term survival. CVA was defined as any clinical deficit lasting longer than 24 hours and TIA was defined as focal neurologic deficit with normal cerebral imaging and resolving in $<24$ hours. Postoperative complications included CVA or TIA, renal failure, packed red blood cell transfusion, and reoperation for bleeding. Ventilator times, intensive care unit (ICU) time, and hospital length of stay (LOS) were also measured. Mortality data was collected from hospital records, routine patient follow-up, state Department of Public Health, and query of the Social Security Death Index.

\section{Statistical Analyses}

Evaluation of dichotomous variables was done with Fisher exact test, and results are presented as percent and number of cases. Continuously distributed variables were evaluated using Student $t$ test with Levine's test for homogeneity of variance; these data are presented as means and standard deviations. Mann-Whitney $U$ tests were used to evaluate nonnormally distributed continuous variables and are presented as medians and interquartile ranges (IQRs). Risk factors for late mortality were evaluated using a multivariable Cox proportional hazards model; tested variables were selected on the basis of known risk factors from the literature, those that differed significantly between groups, and clinically important variable expected to affect survival. Interaction terms were examined. All statistical analyses were performed using SPSS 13.0 (IBM SPSS Inc, Armonk, NY).

\section{RESULTS \\ Study Population}

Out of 467 patients who underwent noncomplex hemiarch surgery, 276 received DHCA alone (59.1\%), 114 received DHCA with ACP $(24.4 \%)$, and 77 received DCHA with RCP $(16.4 \%)$. In the ACP group, 8 out of 114 patients used DHCA with both ACP and RCP. We 
TABLE 1. Preoperative characteristics of patients undergoing each cerebral protection method

\begin{tabular}{|c|c|c|c|c|c|c|}
\hline \multirow[b]{2}{*}{ Characteristic } & \multirow{2}{*}{$\frac{\text { DHCA only }}{(n=276)}$} & \multirow{2}{*}{$\frac{\text { DHCA w/ACP }}{(n=114)}$} & \multirow{2}{*}{$\frac{\text { DHCA w/RCP }}{(\mathrm{n}=77)}$} & \multicolumn{3}{|c|}{$\boldsymbol{P} \leq$} \\
\hline & & & & $1 \mathrm{v} 2$ & $1 \times 3$ & $2 \times 3$ \\
\hline Age (y) & $61.1 \pm 13.9$ & $61.6 \pm 13.3$ & $64.4 \pm 13.0$ & .740 & .059 & .162 \\
\hline$>80$ & $8.0(22)$ & $8.8(10)$ & $10.3(8)$ & .840 & .496 & .803 \\
\hline Women & $32.8(91)$ & $28.1(32)$ & $32.1(25)$ & .401 & 1.000 & .630 \\
\hline Renal failure & $2.2(6)$ & $3.5(4)$ & $2.6(2)$ & .487 & .690 & 1.000 \\
\hline Preop creatinine & $1.1 \pm 0.6$ & $1.0 \pm 0.4$ & $1.0 \pm 0.4$ & .654 & .860 & .526 \\
\hline Diabetes & $10.9(30)$ & $7.9(9)$ & $7.7(6)$ & .460 & .526 & 1.000 \\
\hline Hypercholesterolemia & $52.2(144)$ & $50.9(58)$ & $47.4(37)$ & .825 & .522 & .662 \\
\hline Hypertension & $63.0(174)$ & $66.7(76)$ & $61.5(47)$ & .562 & .895 & .539 \\
\hline Cardiogenic shock & $1.1(3)$ & $1.8(2)$ & $2.6(2)$ & .632 & .304 & 1.000 \\
\hline Preop CVA & $3.6(10)$ & $7.9(9)$ & $2.6(2)$ & .117 & 1.000 & .204 \\
\hline Peripheral vascular disease & $37.6(104)$ & $18.4(21)$ & $21.8(17)$ & .001 & .010 & .584 \\
\hline Family history of CAD & $17.5(48)$ & $21.1(24)$ & $17.9(14)$ & .393 & .866 & .713 \\
\hline \multicolumn{7}{|l|}{ NYHA functional class } \\
\hline I & $38.0(105)$ & $33.3(38)$ & $34.6(27)$ & .420 & .690 & .877 \\
\hline II & $42.0(116)$ & $46.5(53)$ & $38.5(30)$ & .433 & .695 & .327 \\
\hline III & $16.3(45)$ & $17.5(20)$ & $23.1(18)$ & .767 & .178 & .358 \\
\hline IV & $3.6(10)$ & $2.6(3)$ & $3.8(3)$ & .764 & 1.000 & .687 \\
\hline Ejection fraction $(\%)$ & $60(50-65)$ & $60(55-65)$ & $60(55-60)$ & .028 & .685 & .140 \\
\hline Emergency & $6.5(18)$ & $7.9(9)$ & $9.0(7)$ & .663 & .456 & .796 \\
\hline Previous $\mathrm{CABG}$ or valve procedure & $12.3(34)$ & $12.3(14)$ & $10.3(8)$ & 1.000 & .696 & .818 \\
\hline \multicolumn{7}{|l|}{ Indication for aorta surgery } \\
\hline Aneurysm & $88.8(245)$ & $86.0(98)$ & $85.9(66)$ & .494 & .434 & 1.000 \\
\hline Acute dissection & $9.4(26)$ & $10.5(12)$ & $12.8(10)$ & .711 & .394 & .648 \\
\hline Chronic dissection & $1.8(5)$ & $3.5(4)$ & $1.3(1)$ & .294 & 1.000 & .650 \\
\hline
\end{tabular}

Values are given as mean \pm standard deviation, \% (n), or median (interquartile range). $D H C A$, Deep hypothermic circulatory arrest; $A C P$, antegrade cerebral perfusion; $R C P$, retrograde cerebral perfusion; $C V A$, cerebrovascular accident; $C A B G$, coronary artery bypass graft; $C A D$, coronary artery disease; $N Y H A$, New York Heart Association.

included these patients in ACP group because the RCP in these patients was mainly used for deairing and removing debris. The study follow-up time was 2159 patient years, with a median observation time of 4.3 years (IQR, 2.2-6.7 years).

Table 1 shows the preoperative characteristics in each group. Patients in the RCP group tended to be older than in the DHCA group $(64.4 \pm 13.0$ years vs $61.1 \pm 13.9$ years, respectively; $P=.059)$, but similar to patients in the ACP group $(61.6 \pm 13.3$ years; $P>.1)$. There was a higher incidence of peripheral vascular disease in patients in the DHCA group $(37.6 \%)$ compared with patients in the ACP group $(18.4 \% ; P=.001)$ and RCP group $(21.8 \%$; $P=.010)$. Preoperative stroke was similar across groups (3.6\% DHCA only, $7.9 \%$ ACP group, $2.6 \%$ RCP group; all $P$ values $>.1)$. Reoperation rates were $12.3 \%$ in the DHCA group, $12.3 \%$ in the ACP group, and $10.3 \%$ in the RCP group $(P>.6)$. All other preoperative characteristics were also similar, including cardiogenic shock, hypertension, diabetes, and renal failure.

Indication for aortic surgery was aneurysm in $88.8 \%$ for the DHCA group, $86 \%$ for ACP group, and $85.9 \%$ for RCP group, and were all statistically similar $(P>.4)$. The remainder surgeries were for acute $(9.4 \%$ vs $10.5 \%$ vs $12.8 \%)$ and chronic (1.8\% vs $3.5 \%$ vs $1.3 \%)$ dissection.
Emergency surgery was performed in $6.5 \%$ for patients in the DHCA group, $7.9 \%$ for patients in the ACP group, and $9.0 \%$ in patients in the RCP group $(P>.4)$.

\section{Concomitant Procedures}

Concomitant procedures and cannulation techniques performed during the noncomplex hemiarch surgery are listed in Table 2. Patients in the DHCA group had more concomitant aortic valve replacement compared with patients in the ACP group $(81.1 \%$ vs $71.1 \% ; P=.031)$ and in the RCP group $(67.7 \% ; P=.013)$. Also, when compared with patients in the RCP group, patients in the DHCA group had a tendency toward fewer concomitant mitral valve procedures (DHCA $3.6 \%$ vs RCP 9.0\%; $P=.067$ ) and tricuspid procedure (DHCA $0.8 \%$ vs RCP $3.9 \% ; P=.071)$. The rate of concomitant coronary artery bypass graft procedures performed was similar across all groups (DHCA $21.5 \%$ vs ACP $22.8 \%$ vs RCP $19.2 \%$; all $P$ values $>.5$ ).

\section{Intraoperative Variables}

Arterial cannulation in the DHCA-only group was aortic in $74.3 \%$, femoral in $13 \%$, and axillary in $12.7 \%$; for patients in the ACP group arterial cannulation was aortic in $44.7 \%$, axillary in $50 \%$, femoral in $4.4 \%$, and innominate 
TABLE 2. Intraoperative data by each cerebral protection method

\begin{tabular}{|c|c|c|c|c|c|c|}
\hline \multirow[b]{2}{*}{ Data } & \multirow[b]{2}{*}{ DHCA only $(n=276)$} & \multirow[b]{2}{*}{ DHCA w/ACP $(n=114)$} & \multirow[b]{2}{*}{ DHCA w/RCP $(n=77)$} & \multicolumn{3}{|c|}{$\boldsymbol{P} \leq$} \\
\hline & & & & $1 \mathrm{v} 2$ & $1 \mathbf{v} 3$ & $2 \times 3$ \\
\hline \multicolumn{7}{|l|}{ Concomitant procedure } \\
\hline CABG & $21.5(59)$ & $22.8(26)$ & $19.2(15)$ & .789 & .754 & .595 \\
\hline Aortic valve & $81.1(224)$ & $71.1(81)$ & $67.7(52)$ & .031 & .013 & .633 \\
\hline Mitral valve & $3.6(10)$ & $6.1(7)$ & $9.0(7)$ & .282 & .067 & .573 \\
\hline Tricuspid valve & $0.8(2)$ & $1.8(2)$ & $3.9(3)$ & .584 & .071 & .394 \\
\hline \multicolumn{7}{|l|}{ Arterial cannulation } \\
\hline Aortic & $74.3(205)$ & $44.7(51)$ & $84.6(66)$ & & & \\
\hline Femoral & $13.0(36)$ & $4.4(5)$ & $9.0(7)$ & & & \\
\hline Axillary & $12.7(35)$ & $50.0(57)$ & $6.4(5)$ & & & \\
\hline Innominate & 0 & $0.9(1)$ & 0 & & & \\
\hline Lowest temperature $\left({ }^{\circ} \mathrm{C}\right)$ & $18.0(17.0-19.7)$ & $18.0(18.0-19.3)$ & $18.0(17.8-20)$ & .001 & .011 & .784 \\
\hline Perfusion time (min) & $193(158-239)$ & $217(170-272)$ & $201(158-246)$ & .005 & .800 & .046 \\
\hline Crossclamp time (min) & $127(94-172)$ & $157(113-186)$ & $143(104-192)$ & .002 & .073 & .482 \\
\hline DHCA time (min) & $21(15-28)$ & $6(3-11)$ & $4(1-14)$ & .001 & .001 & .126 \\
\hline \multicolumn{7}{|l|}{ Cerebral perfusion time (min) } \\
\hline Antegrade & & $24(20-30)$ & & & & \\
\hline Retrograde & & $4(2-5)$ & $15(12-20)$ & & & \\
\hline Total lower body ischemic time & $21(15-28)$ & $30(25-40)$ & $22(16-29)$ & .001 & .298 & .001 \\
\hline Transfused pRBC units & $3(2-6)$ & $3(2-4)$ & $2(2-4)$ & .697 & .626 & .806 \\
\hline
\end{tabular}

Values are given as \% (n) or median (interquartile range). $D H C A$, Deep hypothermic circulatory arrest; $A C P$, antegrade cerebral perfusion; $R C P$, retrograde cerebral perfusion; $C A B G$, coronary artery bypass graft; $p R B C$, packed red blood cell.

in $0.9 \%$; for patients in the RCP group arterial cannulation was aortic in $84.6 \%$, femoral in $9 \%$, and axillary in $6.4 \%$.

Other perioperative outcomes are also shown in Table 2. When compared with patients in the ACP group, patients in the DHCA group had significantly shorter perfusion time (DHCA 193 minutes vs ACP 217 minutes; $P=.005$ ) and crossclamp time (DHCA 127 minutes vs ACP 157 minutes; $P=.002)$. The total lower body ischemic time, measured by the sum of DHCA, ACP, and RCP time, was significantly longer in patients in the ACP group compared with patients in the DHCA group (ACP 30 minutes vs DHCA 21 minutes; $P=.001$ ) and in the RCP group (vs RCP 22 minutes; $P=.001)$. Transfusion of packed red blood cells were similar across all groups.

\section{Postoperative Outcomes}

Postoperative outcomes are listed in Table 3. Operative mortalities were statistically similar across all groups (DHCA $4.7 \%$, ACP $2.6 \%$, and RCP $2.6 \%$; all $P$ values $>$.4). Overall adverse cerebrovascular outcomes were similar among groups for permanent stroke (DHCA 4.3\%, ACP 5.3\%, and RCP 6.4\%; all $P$ values $>.5$ ) and transient ischemic attacks (DHCA $1.1 \%$, ACP $0.9 \%$, and RCP $0 \%$; all $P$ values $>.5$ ). Other complication rates, including reoperation for bleeding and renal failure were also similar.

Median ventilation time was longer in patients in the RCP group (10.3 hours) compared with patients in the ACP (7.0 hours; $P=.015)$ and DHCA groups (8.2 hours; $P=.076$ ). However median ICU and postoperative LOS did not differ substantially between groups (Table 3 ).

TABLE 3. Comparison of postoperative outcomes by cerebral protection method

\begin{tabular}{|c|c|c|c|c|c|c|}
\hline \multirow[b]{2}{*}{ Outcome } & \multirow{2}{*}{$\begin{array}{c}\text { DHCA only } \\
(n=276)\end{array}$} & \multirow{2}{*}{$\frac{\text { DHCA w/ACP }}{(n=114)}$} & \multirow{2}{*}{$\frac{\text { DHCA w/RCP }}{(n=77)}$} & \multicolumn{3}{|c|}{$\boldsymbol{P} \leq$} \\
\hline & & & & $1 \mathrm{v} 2$ & $1 \times 3$ & $2 \times 3$ \\
\hline Operative mortality & $4.7(13)$ & $2.6(3)$ & $2.6(2)$ & .415 & .537 & 1.000 \\
\hline Reoperation for bleeding & $1.8(5)$ & $4.4(5)$ & $2.6(2)$ & .164 & .652 & .703 \\
\hline New-onset CVA & $5.4(15)$ & $6.2(7)$ & $6.4(5)$ & .811 & .780 & 1.000 \\
\hline Stroke & $4.3(12)$ & $5.3(6)$ & $6.4(5)$ & .791 & .546 & .756 \\
\hline TIA & $1.1(3)$ & $0.9(1)$ & $0.0(0)$ & .500 & 1.000 & 1.000 \\
\hline New-onset renal failure & $2.5(7)$ & $3.5(4)$ & $3.8(3)$ & .737 & .464 & 1.000 \\
\hline Transfused pRBC units & $3(2-7)$ & $3(3-5)$ & $2(2-6)$ & .580 & .796 & .911 \\
\hline Vent time (h) & $8.2(5.1-15.6)$ & $7.0(4.8-14.0)$ & $10.3(6.3-18.5)$ & .166 & .076 & .015 \\
\hline Intensive care unit stay (h) & $47.0(25-86)$ & $47.0(26-91)$ & $44.5(24-92)$ & .973 & .559 & .506 \\
\hline Length of stay (d) & $7(5-10)$ & $7(6-10)$ & $7(5-11)$ & .197 & .894 & .369 \\
\hline
\end{tabular}

Values are given as \% (n) or median (interquartile range). $D H C A$, Deep hypothermic circulatory arrest; $A C P$, antegrade cerebral perfusion; $R C P$, retrograde cerebral perfusion; $C V A$, cerebrovascular accident; TIA, transient ischemic attack; $P R B C$, packed red blood cell. 
TABLE 4. Cox regression analysis: Significant predictors of postoperative survival

\begin{tabular}{lcccr}
\hline & & & \multicolumn{2}{c}{$\mathbf{9 5 \%}$ CI } \\
\cline { 4 - 6 } \multicolumn{1}{c}{ Predictor } & $\boldsymbol{P} \leq$ & HR & Lower & Upper \\
\hline Preoperative renal failure & .056 & 3.167 & 0.970 & 10.342 \\
Age (y) & .001 & 1.068 & 1.043 & 1.092 \\
Total lower body ischemic time (min) & .001 & 1.032 & 1.015 & 1.049 \\
Diabetes & .003 & 2.457 & 1.357 & 4.464 \\
Nonsignificant variables tested & & & & \\
$\quad$ Lowest system temperature & .180 & & & \\
Previous procedure & .346 & & & \\
Hypercholesterolemia & .445 & & & \\
$\quad$ NYHA functional class & .713 & & & \\
Smoker & .809 & & & \\
Perfusion method & .861 & & & \\
Family history of CAD & .878 & & & \\
Gender & .912 & & & \\
\hline Overall model performance: -2 log likelihood $=717.446, X^{2}=94.665, d f=6$, \\
$P<.001 . C I$, Confidence interval; $H R$, hazard ratio; NYHA, New York Heart Associ- \\
ation; $C A D$, coronary artery disease.
\end{tabular}

\section{Long-Term Outcomes}

We used a Cox proportional hazards analysis to evaluate predictors of long-term survival. Table 4 shows the significant contributors in the final model. In order of increasing significance, preoperative renal failure (hazard ratio [HR], 3.167; 95\% confidence interval [CI], 0.97-10.342; $P=.056$ ), diabetes (HR, 0.407; 95\% CI, 0.224-0.737; $P=.003$ ), age in years (HR, 1.068; 95\% CI, 1.043$1.092 ; P \leq .001)$, and total lower body ischemic time (HR, 1.032; 95\% CI, 1.015-1.049; $P \leq .001$ ) were associated with shorter postoperative survival. Neither lower body temperature $(P=.180)$ nor perfusion method $(P=.861)$ was significantly predictive of postoperative survival. Other noncontributory variables tested included reoperation, hypercholesterolemia, New York Heart Association functional classification, smoking history, family history of coronary artery disease, and gender. Figure 1 shows the survival curves of the 3 perfusion groups.

\section{DISCUSSION}

The results of our study demonstrated that DHCA alone without adjunctive strategy had similar operative mortality, morbidity, and long-term survival compared with adjunctive methods of ACP and/or RCP in patients undergoing noncomplex hemiarch surgery. Total lower body ischemic time, perfusion time, and aortic crossclamp time was shorter in DHCA alone compared with ACP, whereas neurologic complication rates and lengths of ICU stay and total LOS were similar across groups. These finding support that DHCA alone is an adequate cerebral protection strategy during noncomplex hemiarch surgery.

There has been no consensus about which cerebral protection strategy is superior for aortic arch surgery. Multiple retrospective studies have shown contradictory outcomes in mortality and neurologic complications. ${ }^{8,10-12}$ Even in a study showing a survival benefit with $\mathrm{ACP}$, this benefit was limited to total aortic arch surgery. ${ }^{9}$

The Achilles heel of DHCA alone as a cerebral protection strategy has been that the risks of neurologic dysfunction increase after a short period. For this reason, advocates of adjunctive cerebral protection methods have criticized DHCA alone. Gega and colleagues ${ }^{6}$ found that DHCA $>40$ minutes was associated with increased mortality and stroke rate as high as $13 \%$. Other investigators have claimed that neurologic risks increase after only 20 to 30 minutes of circulatory arrest. ${ }^{13,14}$ In noncomplex hemiarch surgery, systemic perfusion can be restarted after a quick distal anastomosis. As shown in our study, it is possible to perform this procedure in a short time period. Our median DHCA time was 21 minutes (IQR, 15 to 28 minutes). This technique simplifies the field ${ }^{1}$ and avoids the cumbersome adjunctive cannulation of axillary or innominate artery needed in ACP with attendant risks. Schachner and colleagues ${ }^{15}$ reported technical problems in $14 \%$ and a complication rate of $11 \%$ using right axillary cannulation for aortic surgery. ${ }^{15}$

There are disadvantages to using ACP and RCP. For ACP, there is no standardization of appropriate flow rates. ${ }^{2} \mathrm{Hy}$ perperfusion can lead to cerebral edema whereas hypoperfusion can cause cerebral damage. There is also concern for particulate embolism and vascular injury during cannulation. RCP is becoming less popular given the evidence of less oxygen reaching the brain and more blood flowing into the collaterals rather than the brain. ${ }^{16}$

Neurologic complications are 1 of the most serious adverse events following cardiac surgery. The stroke rate in arch surgery has been reported to be $0 \%$ to $15 \% .^{8-12}$ Our results are well within this range. One randomized control study compared the cerebral protection strategies in aortic arch surgery ${ }^{7}$ and showed that DHCA alone was superior in postoperative long-term neurocognitive tests. However this study had a small number of patients $(n=10)$ in each group. Some retrospective studies have shown increased neurologic dysfunction with DHCA alone, ${ }^{11,12,17}$ but most studies included both hemiarch and total arch surgery. Increasing DHCA time is a risk factor for stroke $^{18}$; therefore, noncomplex hemiarch surgery with shorter DHCA time should be associated with fewer neurologic events. In our study of hemiarch surgery alone, the outcomes were similar across all groups.

Similar to other studies, the DHCA group in our study also had shorter cardiopulmonary bypass and aortic crossclamp times. ${ }^{8,9}$ There are several possible explanations for this. First, lower body ischemic time was shorter in the DHCA group. The lack of an adjunctive method may drive a surgeon to complete the anastomosis faster. Second, concomitant procedures such as mitral and tricuspid valve surgery may have contributed to longer bypass time in the ACP group. Finally, only 3 surgeons performed this DHCA 


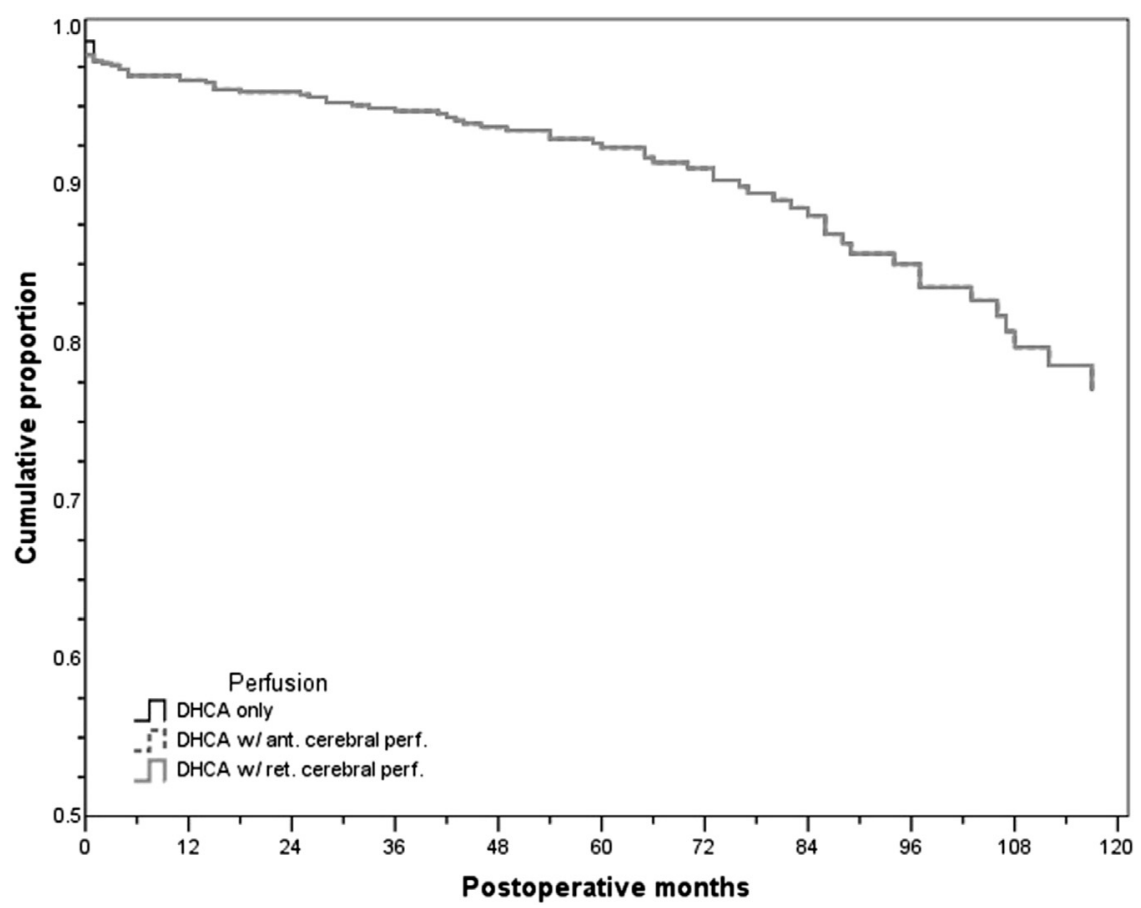

FIGURE 1. Cox regression analysis for survival after aortic valve replacement by preoperative ejection fraction. $D H C A$, Deep hypothermic circulatory arrest.

technique when noncomplex hemiarch replacement was performed and may have created bias.

Our Cox proportional hazards analysis showed that preoperative renal failure, diabetes, increased age, and longer total lower body ischemic time were associated with shortened survival. This emphasizes the importance of performing the anastomosis quickly to keep the circulatory arrest time short. Our findings are in line with previous reports identifying age, ${ }^{18}$ preoperative renal failure, ${ }^{19}$ and urgent/emergent operation $^{20}$ as risk factors for mortality. However in our study other risk factors thought to be important such as lowest systemic temperature, reoperation, and gender were not significant predictors. Most importantly the method of cerebral protection was not a predictor for survival.

Recently cerebral protection with ACP and moderate hypothermia $\left(22^{\circ} \mathrm{C}-28^{\circ} \mathrm{C}\right)$ has been reported to improve operative mortality, reduce neurologic complications, and shorten cardiopulmonary bypass time compared with DHCA. ${ }^{20,21}$ Also, unilateral ACP allowed 30 to 50 minutes of circulatory arrest, whereas bilateral ACP allowed 86 to 164 minutes with low neurologic complication rate $<5 \%$. ${ }^{22}$ We have not applied the moderate hypothermia methods to our practice, and it is beyond our study to analyze whether these methods will improve the outcomes in patients in the ACP group compared with DHCA alone.

Our study is 1 of the largest studies to compare cerebral protection strategies focusing on noncomplex hemiarch surgeries. We did not find any differences in operative mortality, stroke rate, or postoperative survival. We also identified multiple risk factors for patients undergoing noncomplex hemiarch surgery for aortic aneurysm and acute or chronic aortic dissection. Among the various risks, cerebral protection strategy was not a risk factor by itself. These findings confirm the safety of DHCA alone without adjunctive strategy in patients undergoing this type of surgery.

\section{Limitations}

This was a single-institution nonrandomized retrospective study and is subject to all the limitations inherent in such a design. Our institution is a tertiary hospital, and our results may not be generalizable to other patient populations. The type of cerebral protection used was at the surgeon's discretion, which may be a source of bias. Selection bias may introduce the possibility that our findings reflect practitioner differences as well as differences in cerebral protection methods. Our study contained too few patients to allow for meaningful subgroup analyses to further quantify and evaluate these issues. Regardless this is one of the largest studies conducted regarding this subject.

\section{CONCLUSIONS}

DHCA alone without an adjunctive cerebral protection strategy is a safe and effective method for noncomplex 
hemiarch operations. Outcomes, including mortality, neurologic complications, and long-term survival using DHCA alone were comparable to adjunct cerebral protection methods.

\section{References}

1. Griepp RB, Stinson EB, Hollingsworth JF, Buehler D. Prosthetic replacement of the aortic arch. J Thorac Cardiovasc Surg. 1975;70:1051-63.

2. Chau KH, Ziganshin BA, Elefteriades JA. Deep hypothermic circulatory arrest: real-life suspended animation. Prog Cardiovasc Dis. 2013;56:81-91.

3. Reich DL, Uysal S, Sliwinski M, Ergin MA, Kahn RA, Konstadt SN, et al. Neuropsychologic outcome after deep hypothermic circulatory arrest in adults. $J$ Thorac Cardiovasc Surg. 1999;117:156-63.

4. Immer FF, Lippeck C, Barmettler H, Berdat PA, Eckstein FS, Kipfer B, et al. Improvement of quality of life after surgery on the thoracic aorta: effect of antegrade cerebral perfusion and short duration of deep hypothermic circulatory arrest. Circulation. 2004;110:II250-5.

5. Uysal S, Mazzeffi M, Lin HM, Fischer GW, Griepp RB, Adams DH, et al. Internet-based assessment of postoperative neurocognitive function in cardiac and thoracic aortic surgery patients. J Thorac Cardiovasc Surg. 2011;141: 777-81.

6. Gega A, Rizzo JA, Johnson MH, Tranquilli M, Farkas EA, Elefteriades JA. Straight deep hypothermic arrest: experience in 394 patients supports its effectiveness as a sole means of brain preservation. Ann Thorac Surg. 2007;84: 759-66.

7. Svensson LG, Nadolny EM, Penney DL, Jacobson J, Kimmel WA, Entrup MH, et al. Prospective randomized neurocognitive and S-100 study of hypothermic circulatory arrest, retrograde brain perfusion, and antegrade brain perfusion for aortic arch operations. Ann Thorac Surg. 2001;71:1905-12.

8. Matalanis G, Hata M, Buxton BF. A retrospective comparative study of deep hypothermic circulatory arrest, retrograde, and antegrade cerebral perfusion in aortic arch surgery. Ann Thorac Cardiovasc Surg. 2003;9:174-9.

9. Sundt TM 3rd, Orszulak TA, Cook DJ, Schaff HV. Improving results of open arch replacement. Ann Thorac Surg. 2008;86:787-96.

10. Apaydin AZ, Islamoglu F, Askar FZ, Engin C, Posacioglu H, Yagdi T, et al. Immediate clinical outcome after prolonged periods of brain protection: retrospective comparison of hypothermic circulatory arrest, retrograde, and antegrade perfusion. J Cardiac Surg. 2009;24:486-9.
11. Shihata M, Mittal R, Senthilselvan A, Ross D, Koshal A, Mullen J, et al. Selective antegrade cerebral perfusion during aortic arch surgery confers survival and neuroprotective advantages. J Thorac Cardiovasc Surg. 2011;141:948-52.

12. Misfeld M, Leontyev S, Borger MA, Gindensperger O, Lehmann S, Legare JF et al. What is the best strategy for brain protection in patients undergoing aortic arch surgery? A single center experience of 636 patients. Ann Thorac Surg. 2012; 93:1502-8.

13. Griepp RB, Di Luozzo G. Hypothermia for aortic surgery. J Thorac Cardiovase Surg. 2013;145(Suppl):S56-8.

14. Appoo JJ, Augoustides JG, Pochettino A, Savino JS, McGarvey ML, Cowie DC et al. Perioperative outcome in adults undergoing elective deep hypothermic circulatory arrest with retrograde cerebral perfusion in proximal aortic arch repair: evaluation of protocol-based care. J Cardiothorac Vasc Anesth. 2006;20:3-7.

15. Schachner T, Nagiller J, Zimmer A, Laufer G, Bonatti J. Technical problems and complications of axillary artery cannulation. Eur J Cardiothorac Surg. 2005;27: 634-7.

16. Reich DL, Uysal S, Ergin MA, Griepp RB. Retrograde cerebral perfusion as a method of neuroprotection during thoracic aortic surgery. Ann Thorac Surg. 2001;72:1774-82.

17. Czerny M, Fleck T, Zimpfer D, Dworschak M, Hofmann W, Hutschala D, et al Risk factors of mortality and permanent neurologic injury in patients undergoing ascending aortic and arch repair. J Thorac Cardiovasc Surg. 2003; 126:1296-301

18. Khaladj N, Shrestha M, Meck S, Peterss S, Kamiya H, Kallenbach K, et al. Hy pothermic circulatory arrest with selective antegrade cerebral perfusion in ascending aortic and aortic arch surgery: a risk factor analysis for adverse outcome in 501 patients. J Thorac Cardiovasc Surg. 2008;135:908-14.

19. Ogino H, Sasaki H, Minatoya K, Matsuda H, Tanaka H, Watanuki H, et al Evolving arch surgery using integrated antegrade selective cerebral perfusion: impact of axillary artery perfusion. J Thorac Cardiovasc Surg. 2008;136:641-8.

20. Tsai JY, Pan W, Lemaire SA, Pisklak P, Lee VV, Bracey AW, et al. Moderate hypothermia during aortic arch surgery is associated with reduced risk of early mortality. J Thorac Cardiovasc Surg. 2013;146:662-7.

21. Wozniak G, Dapper F, Zickmann B, Gehron J, Hehrlein FW. Selective cerebra perfusion via innominate artery in aortic arch replacement without deep hypothermic circulatory arrest. Int J Angiol. 1999;8:50-6.

22. Malvindi PG, Scrascia G, Vitale N. Is unilateral antegrade cerebral perfusion equivalent to bilateral cerebral perfusion for patients undergoing aortic arch surgery? Interact Cardiovasc Thorac Surg. 2008;7:891-7.

\title{
EDITORIAL COMMENTARY
}

\section{Belt and suspenders: Can we keep them in the drawer?}

\author{
Joseph Schmoker, MD
}

See related article on pages 2911-7.

From the Division of Cardiothoracic Surgery, Fletcher Allen Health Care, Burlington, Vt.

Disclosures: Joseph Schmoker has received honoraria from Medtronic, Inc, for training and proctoring services.

Received for publication Sept 27, 2014; accepted for publication Sept 28, 2014; available ahead of print Oct 22, 2014.

Address for reprints: Joseph Schmoker, MD, Division of Cardiothoracic Surgery, Fletcher Allen Health Care, 111 Colchester Ave, MCHV Campus Fletcher 4,

Burlington, VT 05401 (E-mail: joseph.schmoker@vtmednet.org).

J Thorac Cardiovasc Surg 2014;148:2917-9

$0022-5223 / \$ 36.00$

Copyright $\odot 2014$ by The American Association for Thoracic Surgery

http://dx.doi.org/10.1016/j.jtcvs.2014.09.101
In this issue of the Journal, Kaneko and colleagues ${ }^{1}$ report their institutional experience with cerebral protection strategies in patients undergoing proximal aortic arch resection for aneurysms and dissection. This is a large contemporary series spanning a 10-year period, and at face value the results show that the adjunctive protection measures of antegrade cerebral perfusion (ACP) or retrograde cerebral perfusion (RCP) offer no added benefit to deep hypothermic circulatory arrest (DHCA) alone in the prevention of cerebral morbidity, such as stroke or transient ischemic attack. This complements a recently published large series of patients from another experienced group who also reported low cerebral morbidity with the use of DHCA alone for hemiaortic arch replacement. ${ }^{2}$ 